\title{
EDITORIAL
}

\section{Lung versus heart-lung transplantation for cystic fibrosis: is the debate still open?}

\author{
P. Thomas
}

$\mathbf{A}$ lthough medical management has considerably improved, cystic fibrosis (CF) remains a major cause of mortality from suppurative lung disease, in children and young adults. Lung transplantation is currently the only available efficient treatment of the life-limiting aspects of the condition to achieve improved quality of life and long-term survival in these patients, who stand to benefit more from transplantation than any other diagnostic group [1]. In this issue of the European Respiratory Journal, GANESH et al. [2] present the results of the UK Cardiothoracic Transplant Audit, with similar outcomes achieved by heart-lung transplantation (HLT) and bilateral lung transplantation (BLT) in CF recipients, thereby reopening a debate that was considered closed for a while. Indeed, very few HLTs are still performed for this indication, and the main reason for this is the trend for fewer HLT procedures being performed worldwide, which is reflected again in the international figures from last year's results of the Registry of the International Society of Heart and Lung Transplantation [3]. Since $\sim 50 \%$ of CF patients die on the waiting list due to a scarcity in the supply of donor thoracic organs, current efforts involve any attempt to expand the lung donor pool: specifically, liberalisation of donor criteria [4] and the use of non-heart-beating donors for adult recipients [5], lung bipartitioning and lobar transplantation [6], as well as living-lung donor transplantation for paediatric recipients [7].

Since the first application in the setting of CF in 1983, a HLT [8], surgical techniques have markedly evolved. Until the beginning of the 1990s, HLT was the gold standard because of the initial experience and confidence acquired by transplant teams in other groups of patients. Dismal early experiences with defective tracheal or bronchial healing in en bloc doublelung transplantation highlighted the importance of the bronchial artery circulation as nutritive arterial blood supply to the transplanted lungs, which was suggested as early as 1950 [9]. The innovative concept of bronchial artery revascularisation [10] did not gain wide acceptance, and simpler procedures were investigated. BLT, consisting of a sequential bilateral single-lung transplantation [11], offers several advantages that currently define it as the procedure of choice.

First, it saves the recipient heart, the replacement of which is unnecessary in almost all cases from a medical point of view and, thus, ethically questionable. It obviates the necessity to

CORRESPONDENCE: P. Thomas, Dept of Thoracic Surgery and Lung Transplantation, Sainte Marguerite University Hospital, 270 bvd Sainte Marguerite, 13274 Marseille, France. Fax: 33 491744590. E-mail: pascal-alexandre.thomas@mail.ap-hm.fr transplant a denervated heart from a brain-dead donor and the possibility of acute cardiac rejection and late-graft coronary artery disease. Considering the last complication, the followup time of the study by GANESH et al. [2], at 4 yrs, is not long enough to judge this effect. With increasing observational times, this may change in the future, and CF patients having received a heart-lung graft might well be at risk, not only for bronchiolar but also for vascular chronic rejection. Conversely, the possibility to implant the HLT recipient heart in another recipient (domino heart transplantation) is an alternative to optimise organ allocation. It may provide better early and long-term results than those of cadaveric donor grafts, given that such heart grafts are spared from the deleterious effects of brain death. Furthermore, it has been suggested that hearts from living CF donors were particularly suitable organs for the subset of heart transplantation recipients with high pulmonary vascular resistance [12]. It assumes, however, serious organisational limitations considering the shorter tolerable preservation times in heart transplantations and HLTs when compared with lung transplantation.

Undeniably, the most striking finding of the study by GANESH et al. [2] is the improved use of hearts from domino donors when compared with that of hearts from cadaveric doublelung donors. Even if there is an attempt to identify those reasons why almost $40 \%$ of hearts of donors from which the lungs were successfully transplanted were not used, its rationale remains hardly comprehensible. Intuitively, this might be a specific problem in the local organ retrieval and allocation organisation. Therefore, this finding may not be applicable in most European countries and other parts of the world. Furthermore, another key point has not been addressed: the impact of the use of heart-lung grafts for CF on other diagnostic group patients with congenital heart disease and Eisenmenger's syndrome who truly need both organs, the heart and the lungs, to be replaced.

Secondly, BLT may be accomplished without the need for cardiopulmonary bypass $(\mathrm{CPB})$, which carries the risk of substantial perioperative bleeding. This is particularly relevant in CF recipients in whom bronchial collaterals and dense pleural adhesions are constantly encountered as a result of chronic pulmonary infections and/or previous intervention to the pleural space. This issue, however, remains highly controversial $[13,14]$. Proponents of the routine use of $\mathrm{CPB}$ advocate its timesaving advantage by reducing the extraction-implantation delay for the second lung; the optimised exposure to hilar structures it provides, thus avoiding extended manipulation and associated haemodynamic instability; and the avoidance of 
the need of the first implanted lung to entirely sustain the circulating volume, a situation favouring the occurrence of major reperfusion oedema. Opponents argue about its detrimental effects on endothelial permeability and coagulation factors secondary to production of proinflammatory cytokines and humoral mediators, which, in turn, could also result in postoperative haemorrhage and reperfusion injury. In a more secondary way, BLT, in contrast with HLT, may also be performed in some cases through a bilateral thoracotomy, without sternal splitting, thereby minimising the operative trauma, improving post-operative functional recovery, and preventing the potential spread of unilateral complications to the other pleural cavity, as well as post-transplantation sternal complications [15].

Pragmatically, donor shortage is the main limitation of the more widespread application of heart-lung transplantation. Thus, for the indications where alternative options exist, the choice of operation will continue to be primarily dictated by the rules of organ attribution among allocation systems, according to the priority given or not to heart-lung blocks. For this reason, it is totally unrealistic to envisage randomised trials comparing heart-lung transplantation and bilateral lung transplantation in cystic fibrosis recipients, which would have been the means to definitively close this debate.

\section{REFERENCES}

1 Hosenpud JD, Bennett LE, Keck BM, Edwards EB, Novick RJ. Effect of diagnosis on survival benefit of lung transplantation for end-stage lung disease. Lancet 1998; 351: 24-27.

2 Ganesh JS, Rogers CA, Bonser RS, Banner NR. Outcome of heart-lung and bilateral sequential lung transplantation for cystic fibrosis: a UK national study. Eur Respir J 2005; 25: 964-969.

3 Trulock EP, Edwards LB, Taylor DO, Boucek MM, Keck BM, Hertz MI. The Registry of the International Society for Heart and Lung Transplantation: twenty-first official adult heart transplant report- 2004. J Heart Lung Transplant 2004; 23: 804-815.

4 Bhorade SM, Vigneswaran W, McCabe MA, Garrity ER. Liberalization of donor criteria may expand the donor pool without adverse consequence in lung transplantation. J Heart Lung Transplant 2000; 19: 1199-1204.

5 Steen S, Sjoberg T, Pierre L, Liao Q, Eriksson L, Algotsson L. Transplantation of lungs from a non-heartbeating donor. Lancet 2001; 357: 825-829.

6 Couetil JP, Tolan MJ, Loulmet DF, et al. Pulmonary bipartitioning and lobar transplantation: a new approach to donor organ shortage. J Thorac Cardiovasc Surg 1997; 113: 529-537.

7 Cohen RG, Barr ML, Schenkel FA, DeMeester TR, Wells WJ, Starnes VA. Living-related donor lobectomy for bilateral lobar transplantation in patients with cystic fibrosis. Ann Thorac Surg 1994; 57: 1423-1427.

8 Frist WH, Fox MD, Campbell PW, Fiel SB, Loyd JE, Merrill WH. Cystic fibrosis treated with heart-lung transplantation: North American results. Transplant Proc 1991; 23: 1205-1206.

9 Metras H. Note préliminaire sur la greffe totale du poumon chez le chien [Preliminary note on the whole lung transplantation in dogs]. CR Acad Sci III (Paris) 1950; 231: 1176-1177.

10 Couraud L, Baudet E, Martigne C, et al. Bronchial revascularization in double-lung transplantation: a series of 8 patients. Bordeaux Lung and Heart-Lung Transplant Group. Ann Thorac Surg 1992; 53: 88-94.

11 Bisson A, Bonnette P. A new technique for double lung transplantation. "Bilateral single lung" transplantation. J Thorac Cardiovasc Surg 1992; 103: 40-46.

12 Anyanwu AC, Banner NR, Radley-Smith R, Khaghani A, Yacoub $\mathrm{MH}$. Long-term results of cardiac transplantation from live donors: the domino heart transplant. J Heart Lung Transplant 2002; 21: 971-975.

13 Marczin N, Royston D, Yacoub M. Pro: lung transplantation should be routinely performed with cardiopulmonary bypass. J Cardiothorac Vasc Anesth 2000; 14: 739-745.

14 McRae K. Con: lung transplantation should not be routinely performed with cardiopulmonary bypass. J Cardiothorac Vasc Anesth 2000; 14: 746-750.

15 Taghavi S, Birsan T, Seitelberger R, et al. Initial experience with two sequential anterolateral thoracotomies for bilateral lung transplantation. Ann Thorac Surg 1999; 67: 1440-1443. 